\title{
호주 대외원조 개관 ${ }^{1)}$
}

\section{I. 호주 개발원조의 전략적 기초와 새로운 방향}

1 개발협력정책의 기조

$\square$ 개발도상국의 빈곤퇴치와 지속가능발전지원을 통 한 호주의 국익증진

2002년 9월 원조에 관한 새로운 정책 보고서

"Australian Aid: Investing in Growth, Stability and Prosperity”를 통해 호주는" 개발 도상국의 빈곤퇴치와 지속가능발전 지원을 통한 호주의 국익증진"이라고 원조목적을 명시함.

- 원조는 자국의 외교정책과 국익의 중요한 요소 이며 이는 이태지역의 발전, 평화, 안정을 추구 하고 자국의 지속적인 번영에 직결된 이슈들을
해결하기위해 필요한 것임을 강조

- 그러나 장기적 관점에서는 호주의 국익과 원조 효과가 일치하더라도 단기적으로는 일치하지 않을 수 있으며, 따라서 일치하지 않을 경우 수 원국의 장기적 개발효과에 초점을 두어 원조를 실시해야 함.

- 특히 호주의 ODA 주요 담당기관인 호주국제개 발청(AusAID)은 전체 정부 아젠다 안에서 호주 의 국익이 수원국의 이익에 우선하지 않도록 주 된 역할을 수행하여야 함. 개발원조의 인도주의 원칙은 다른 정책 아젠다로부터 독립적이어야 한다는 원칙을 고수하여야 함.

$\square$ 빈곤감소를 위한 성장과 안정성, 번영에의 투자 2001년 발표된“ The Central Integrating Factor of Australia's Aid Program"은 빈곤감소 
는 호주의 개발원조 프로그램의 기본 방향이며 다 음의 4가지 원칙에 기초를 두고 있음을 명시함.

- 빈곤계층에게 혜택을 주는 지속가능하고 포괄 적인 경제성장 기반 형성 지원

- 빈곤계층이 금융, 시장, 소유권, 기술, 건강 및 교육 시스템을 보다 잘 활용할 수 있도록 함으 로서 이들의 생산성 항상을 지원

- 정부와 원조조직체(institutions), 후원자들 (donors)의 빈곤계층에 대한 책임성 강화

- 빈곤계층의 취약성 완화

$\square$ 거버넌스 강조

- 경제성장은 개발과 빈곤감소의 견인차 역할을 수행하며 이는 굿거버넌스 이슈와 밀접하게 연 관되어 있다고 밝힘. 따라서 호주는 수원국의 정책, 기관, 정부시스템의 강화에 역점을 두고 개발원조 프로그램을 수행함.

\section{$\square$ 빈곤완화와 MDGs의 연계강화}

- 거버넌스, 안보, 정부전체적 접근(the whole of government approach)과 빈곤완화전략사이 의 관계가 더 명확해져야 할 필요가 있음. 또한 동 접근방식을 통해 빈곤국가와 국가내 가장 빈 곤한 커뮤니티가 어떻게 혜택을 받을 수 있는지 밝혀야 함.

- 호주는 개도국의 성장을 뒷받침할 수 있는 지속 적이며 안정적인 환경 조성을 중요시 함. 따라 서 개도국의 빈곤감소를 지원하기 위해서는 국 별 상황에 대한 이해와 분석에 기초한 차별화된 접근이 필요함을 강조함. 이러한 측면에서 MDGs는 세계의 개발노력의 중요성에 대한 관
심을 지속시킨다는 점에서 의의가 크나 실질적 인 원조 프로그램의 benchmarks로서 보기는 어렵다는 입장임.

- 호주는 ODA 자체만으로는 MDGs를 달성하기 어려울 것으로 예상하고 실질적인 발전은 무역 의 자유화, 외국인직접투자Foreign Direct Investment), 국내저축의 증대 등 사적인 부 문의 강화를 통해 이루어질 것으로 여김. 따라 서 굿거버넌스와 경제성장을 강조하고 건전한 정책과 제도적 틀 확립에 원조프로그램의 초점 을 둠.

\section{$\square$ 취약국가지원}

- 취약국가지원은 각 국가 상황별 포괄적 접근을 시 도해야 하고, 또한 빈곤층에 대한 자체 지원시스 템의 부족을 보충하며 동시에 개도국 정부의 개혁 을 유도해야 함. 호주는 세계은행 등과 함께 the Low Income Countries Under Stress(LICUS) 접근틀을 개발하기 위해 노력하고 있음.

- 정부시스템의 실패로 인해 지원효과가 빈곤층 에게 미치지 않을 시, 정부의 하위레벨을 통하 거나 지역사회로 직접 전달하는 방법을 취함.

2. 개발협력에 대한 국민적 지지

$\square$ 해외원조에 대한 높은 국민적 지지

- 호주의 ODA에 대한 국민적 지지는 2001년 $85 \%$ 였음.

- 이러한 긍정적 동향은 NGOs 기부금 증가와도 일치하고 있음. NGOs 기부금 증가는 지난 5년 간 연평균 $11 \%$ 이며 2001년 통계에서 호주인의 
절반이 해외원조 기부금을 냈거나 시간을 투자

했다고 밝힘.

- 긴급구호에 대한 국민의 반응은 민감하며 해외 봉사에 관심 또한 높음. 호주는 향후 이러한 국 민적 지지를 유지해야 할 것임.

\section{$\square$ 개발교육}

- 대다수의 국민들이 장기적 개발이 단기적 긴급 구호보다 더 중요하다고 생각하고 있으나 그 지 지도는 1998년보다 $3 \%$ 하락했음. 즉 개발에 대 한 지지도와 개발이슈에 대한 인지도간의 상관 관계는 약한 것으로 나타남.

- AusAID는 NGOs의 개발교육분야에 투자하지 않으며 다만 11개 개발교육그룹(NGO 2, 대학과 교사 협회)을 통해 교육을 실시하고 있음.

\section{ODA 지원현황}

\section{ODA 지원현황}

$\square$ 2003년도 ODA 규모: US\$1,219백만(ODA/GNI $0.25 \%)$

- 2003년 ODA 총액기준으로 DAC 22개 회원 국 중 15 위이며, ODA/GNI 비율 기준으로는 13위임.

- 호주는 1999 2003년 동안 경제성장이 두드러 지고 ODA의 규모도 $9 \%$ 증가하였으나 $\mathrm{ODA} / \mathrm{GNI}$ 비율면에서는 오히려 감소하였음 (1975년 0.65\%).

- GNI/ODA 0.7\% 달성에는 동의하였으나 아직
구체적인 목표달성계획(Timeframe)을 제시하 지 않음.

2. ODA 세부내역

1) ODA 규모 : US\$1,219백만 (2003)

$\square$ 양자간 ODA : US\$ 975백만

$\square$ 다자간 ODA : US\$244백만

- 호주의 다자간 ODA는 개별적인 국제기구에 전략적으로 제공되고 있으며 이들 국제기구들 은 아태지역에서 중요한 역할을 하되, 난민보 호나 HIV/AIDS등 특정분야에 전문적인 역할 을 수행함.

※ 농업발전을 위한 국제펀드(IFAD)에 ODA 제 공을 중단하면서 호주는 동 기구의 역할이 아 태지역 국가들의 개발 우선순위를 고려했을 때 적절하지 않다는 판단 하에 이를 결정하였 다고 밝힘.

<호주 연도별 ODA 및 세부내역 추이>

\begin{tabular}{c|c|c|c|c|c|c|c}
\hline & $87 ~ ~ ' 88$ & $92 ~ ' 93$ & 99 & $\prime 00$ & 01 & '02 & '03 \\
\hline \hline ODA & 864 & 984 & 982 & 987 & 873 & 989 & 1,219 \\
- 양자 & 579 & 727 & 730 & 758 & 660 & 774 & 975 \\
- 다자 & 286 & 257 & 252 & 229 & 212 & 215 & 244 \\
ODA/GNI & 0.41 & 0.36 & 0.26 & 0.27 & 0.25 & 0.26 & 0.25 \\
\hline
\end{tabular}

2) 지역별 지원현황 (양자간 ODA 기준)

- 호주의 원조는 중간수준이나 극동아시아와 태 평양지역에 집중되어 있어 수원국별 호주 ODA 의존율이 높음.

- 각 수원국별 개발원조 총액 중 호주 ODA의 점 유율 
2002 2003년도 상위 10대 수원국 지원 규모 및 점유율>

(단위:US\$백만)

\begin{tabular}{|c|c|c|c|}
\hline 순위 & 국명 & $\begin{array}{c}\text { 지원규모 } \\
\text { (2002 03년 평균) }\end{array}$ & $\begin{array}{c}\text { 총 ODA 대비 점유율 } \\
\text { (2002 } 03 \text { 평균) }\end{array}$ \\
\hline 1 & 파푸아뉴기니 & 195 & $29 \%$ \\
\hline 2 & 인도네시아 & 79 & $12 \%$ \\
\hline 3 & 솔로몬군도 & 44 & $7 \%$ \\
\hline 4 & 베트남 & 38 & $6 \%$ \\
\hline 5 & 동티모르 & 33 & $5 \%$ \\
\hline 6 & 필리핀 & 32 & $5 \%$ \\
\hline 7 & 중국 & 29 & $4 \%$ \\
\hline 8 & 캄보디아 & 21 & $3 \%$ \\
\hline 9 & 이라크 & 21 & $3 \%$ \\
\hline 10 & 방글라데시 & 17 & $3 \%$ \\
\hline \multicolumn{2}{|r|}{ 합계 } & 509 & $77 \%$ \\
\hline \multicolumn{2}{|c|}{ ODA 총규모 } & 874 & \\
\hline
\end{tabular}

<지역별 지원현황(양자간 원조 비율)>

\begin{tabular}{c|c|c|c}
\hline 지역 & 1999 & 2001 & 2003 \\
\hline 사하라이북 아프리카 & 5 & 4 & 4 \\
사하라이남 아프리카 & 1 & 1 & 1 \\
서남아 및 중앙아시아 & 5 & 9 & 7 \\
극동아시아 & 46 & 44 & 36 \\
북중미 & 0 & 0 & 0 \\
남미 & 0 & 0 & 0 \\
중동 & 0 & 0 & 6 \\
오세아니아 & 35 & 42 & 46 \\
유럽 & 8 & 0 & 0 \\
\hline 합 계 & 100 & 100 & 100 \\
\hline
\end{tabular}

므파푸아뉴기니-89\%

골로몬군도 - $75 \%$

극 밖의 오세아니아 국가들 - $38 \%$

- 호주는 지원국가 및 지원분야 선별을 위해 노력

해온 결과, 파푸아뉴기니, 인도네시아, 솔로몬

군도, 베트남, 티모르가 전체 호주 양자간 ODA

의 $58 \%$, 상위 15 대 수원국이 $85 \%$ 를 차지함.

\section{3) 소득 그룹별 지원현황(양자간 ODA 기준)}

<소득그룹별 지원현황(양자간 원조 비율)>

(단위:\%)

\begin{tabular}{c|c|c|c}
\hline 지 역 & $1982-83$ & $1992-93$ & $2002-03$ \\
\hline 최빈개도국(LDCs) & 19.7 & 16.4 & 28.3 \\
기타저소득국(Other LICs) & 63.2 & 55.7 & 49.3 \\
중저소득국(LMICs) & 13.8 & 22.4 & 19.9 \\
고중소득국(UMICs) & 2.8 & 4.7 & 2.5 \\
고소득국(HICs) & - & - & - \\
MADCT & 0.5 & 0.8 & - \\
\hline 합 계 & 100 & 100 & 100 \\
\hline
\end{tabular}

주1)MADCT: More Advanced Developing Countries and Territories (동 국가에 대한 지원은 $\mathrm{OA}(\mathrm{Official} \mathrm{Aid})$ 로 분류.

※자료:OECD, The DAC Journal:Development Co- operation Report 2004, Table 32

<상위 10 대 수원국 추이 및 총 ODA 대비 양자간 원조 비율>

(단위:\%)

\begin{tabular}{c|c|c|c|c|c|c}
\hline 순위 & 국명 (1982- 83) & $\%$ & 국명 (1992- 93) & $\%$ & 국명(2002- 03) & $\%$ \\
\hline 1 & 파푸아뉴기니 & 36 & 파푸아뉴기니 & 37 & 파푸아뉴기니 & 29 \\
2 & 인도네시아 & 13 & 인도네시아 & 12 & 인도네시아 & 12 \\
3 & 중국 & 7 & 필리핀 & 7 & 솔로몬군도 & 7 \\
4 & 필리핀 & 5 & 베트남 & 6 & 베트남 & 6 \\
5 & 태국 & 4 & 중국 & 5 & 동티모르 & 5 \\
6 & 말레이시아 & 4 & 캄보디아 & 4 & 필리핀 & 5 \\
7 & 피지 & 3 & 방글라데시 & 2 & 중국 & 4 \\
8 & 인도 & 2 & 이집트 & 2 & 캄보디아 & 3 \\
9 & 베트남 & 2 & 태국 & 2 & 이라크 & 3 \\
10 & 나잠비크 & 2 & 인도 & 2 & 방글라데시 & 3 \\
\hline & & & & & 77 \\
\hline
\end{tabular}


4) 분야별 지원현황

$\square$ 경제정책과 거버넌스 이슈에 중점을 두고 지원하

고 있음. 동 분야에 대한 지원은 호주 양자간 ODA

의 15\%(2002 03)를 차지하며 DAC의 동분야 지

원 ODA가 $8 \%$ 임을 감안할 때 호주가 거버넌스 이

슈에 초점을 맞추고 있음을 알 수 있음. 또한

2004 2005년에는 동 분야가 33\%에 이를 것으로 예상됨.

<2003년도 분야별 지원실적>

\begin{tabular}{|c|c|c|}
\hline \multicolumn{2}{|c|}{ 분 야 } & 2003년 \\
\hline \multirow{6}{*}{$\begin{array}{c}\text { 사회 및 행정 인프랖 } \\
\text { (Social and } \\
\text { administrative } \\
\text { infrastructure) }\end{array}$} & 교육(기초교육) & $7.7(3.3)$ \\
\hline & 보건(기초보건)2) & $8.2(4.9)$ \\
\hline & 인구 & 2.9 \\
\hline & 식수 및 위생 & 2.4 \\
\hline & 정부 및 시민사회 & 15.2 \\
\hline & 기타 사회인프라/서비스 & 9.2 \\
\hline \multicolumn{2}{|c|}{ 소 계 } & 45.6 \\
\hline 경제인프라 & 교통 및 통신 & 4.5 \\
\hline (Economic & 에너지 & 0.2 \\
\hline infrastructure) & 기타 & 0.8 \\
\hline \multicolumn{2}{|c|}{ 소 계 } & 5.5 \\
\hline \multirow{3}{*}{$\begin{array}{c}\text { 생산 } \\
\text { (Production) }\end{array}$} & 농업 & 6.7 \\
\hline & 제조업, 광업 및 건축 & 0.1 \\
\hline & 무역 및 관광 & 0.5 \\
\hline \multicolumn{2}{|c|}{ 소 계 } & 7.3 \\
\hline \multicolumn{2}{|c|}{ 다부문(Multisector) } & 16.8 \\
\hline \multicolumn{2}{|c|}{ 프로그램원조(Programme assistance) } & 3.6 \\
\hline \multicolumn{2}{|c|}{ 부채탕감(Action relating to debt) $)^{3)}$} & 0.7 \\
\hline \multicolumn{2}{|c|}{ 긴급원조(Emergency aid) } & 14.3 \\
\hline \multicolumn{2}{|c|}{ 행정경비(Administrative expenses) } & 5.7 \\
\hline \multicolumn{2}{|c|}{ 기타(Unspecified) } & 0.5 \\
\hline \multicolumn{2}{|c|}{ 합 계 } & 100 \\
\hline
\end{tabular}

주 1) 학생 및 연수생 포함

2) 인구 및 생식보건

3) 비ODA 부채탕감 포함

※자료:OECD, The DAC Journal : Development Co-operation Report 2004, Table 19
<호주 연도별 ODA 및 세부내역 추이>

(단위:\%)

\begin{tabular}{c|c|c}
\hline 지원년도 & $1982 ~ 83$ & $2002 \sim 03$ \\
\hline 사회/행정 인프라 & 15.0 & 44.0 \\
경제인프라 & 4.7 & 6.7 \\
농업 & 7.3 & 6.6 \\
산업/기타생산 & 3.5 & 0.7 \\
물자/프로그램지원 & 59.5 & 4.7 \\
긴급지원 & 13 & 13.6 \\
기타 & 8.5 & 23.7 \\
\hline
\end{tabular}

※자료:OECD, The DAC Journal:Development Co- operation Report 2004, Table 18

\section{1 굿거버넌스 - 통합적 접근}

$\square$ 굿거버넌스가 개발을 위한 가장 중요한 변수라는 인식 하에 수원국 중앙정부 뿐만 아니라 지방정부 와 민간분야를 대상으로 올바른 통치 기반 형성에 중점 지원

호주의 거버넌스 이슈에 대한 접근은 다음의 5 가 지로 나누어짐.

- 경제.금융 관리의 개선

- 법과 정의의 강화

- 공공분야의 효과성 증진

- 시민사회의 성장

- 민주주의 시스템 강화

$\square$ 동 접근방법들은 국별 원조프로그램에 반영됨.

- 특히 법체계 강화에 중점을 두고 시행함.

- 호주는 굿거버넌스를 위해 국별 상황을 분석하 고 정치, 경제적 측면에서 폭넓게 접근함. 각 분 야별 연결을 통해 시너지 효과 창출에 관심을 
둠. 예를 들어 장학금 제도는 공무원 교육을 통

한 주요 분야의 역량강화(Capacity building)와 굿거버넌스 지원 목표를 동시에 달성할 수 있음.

- 또한 부패척결을 위해 중점 지원함.

2. 잠재력 있는 원조공여국 호주

$\square$ 지난 3년간 인도주의 원조분야에 대해 호주는 ODA 비율을 두배로 증가시켰음. 2003년 긴급재 난구호가 호주 ODA의 $11 \%$ 를 차지하였음.

$\square$ 2004년 인도주의 지원에 대한 새로운 정책을 수 립함. 동 정책은 인도주의 원조의 일관성, 효과, 책 임성을 제고하고 개발과 인도주의 원조간의 관련 성을 강조, 빈곤이 취약성의 근본 원인임을 지적 함. 이러한 맥락에서 호주는 국가와 지역사회의 재 난 및 위험관리 능력를 고양시키는데 중점을 둠.

$\square$ 동 정책은 독립성과 중립을 유지하면서 자연재해, 분쟁 시 보호, 물질적 지원, 역량강화, 예방, 사전 준비에 초점을 맞추고 있음.

3. 분쟁 예방과 평화구축- 새로운 접근과 정책의 변화

$\square$ 솔로몬군도, 피지, 부겐빌 섬에서 발생한 분쟁으 로 인해 호주는 이의 예방과 평화구축을 위한 새로 운 정책적 접근의 필요성을 인식함. 지역안보차원 에서 주변국들의 평화구축 능력을 항상시키고, 안 정성을 확보하고 국제적인 도전에 대응하는 것이 호주 개발협력프로그램의 중요한 부분을 차지함. 호주는 경제적 발전을 위한 전제조건은 안보이며 분쟁은 빈곤에 의해 발생되는 것이라고 강조함. $\square$ 2002년" 평화, 분쟁 그리고 개발 정책"을 새롭게 수립하고 분쟁예방과 평화구축을 위해 세가지 차 원의 접근을 제시함.

- 예방적 차원 : 대화의 활성화, 거버넌스의 강화, 무기밀매의 금지

- 분쟁관리와 분쟁감소 차원 : 인도주의적 지원, 특히 난민과 실향민, 여성과 아동 집중지원

- 분쟁후 관리 차원 : 평화와 화해를 직접 지원하 고 재건과 경제회복 지원

$\square$ 안보문제관리 정책은 국별원조 프로그램에도 반영됨.

4. 교차사안

1) 성인지적 관점

$\square$ 호주는 1999년 DAC 동료평가에서 성평등적 정책 과 정책집행 장치의 개발 면에서 다른 회원국들에 비해 앞서 있다는 평가를 받음.

- 호주의 성인지적 개발정책을 수행하려는 노력 은 호주의 주요 수원국에서의 여성의 지위가 매 우 약하다는 점을 고려할 때 더욱 높게 평가될 수 있음.

$\square$ 성평등은 빈곤감소를 위한 중요한 요소임을 인식 하고 AusAID는 Full- time 젠더이슈 전문가를 고 용할 뿐 아니라 여러 명의 전문가들을 추가적으로 단기 고용하였음.

2) HN/AIDS

$\square$ HIV/AIDS는 이태지역의 정치, 경제, 사회적 발전 에 매우 부정적임을 인식한 호주는 동 분야에 대한 강한 정치적 대응을 하고 있음. 재원의 상당한 배 
분과 포괄적 HIV/AIDS 프로그램의 개발이 이루 어지고 있음. 뿐만 아니라 이태지역 HIV/AIDS 포 럼, 네트워크를 지원하고 있음.

*Asia Pacific Leadership Forum on HIV/AIDS Asia Pacific Regional Networks on HIV/AIDS $\square$ 2004년에 수립된" Meeting the Challenge: Australia's international HIV/AIDS strategy" 는 호주의 개발경험을 바탕으로 수립됨. 동 전략은 특정 HIV/AIDS 프로젝트를 개발하기 보다는 국 별 전략의 교차사안으로 접근하여 더 강하고 체계 적으로 HIV /AIDS 분야에 대응할 수 있도록 함.

\section{IV. 정책일관성}

\section{1 호주 시스템과의 정책적 일관성 강화}

$\square$ 호주는 개발정책일관성이란 개도국의 욕구와 이 해를 세계경제의 진화 속에 함께 고려하는 것이라 고 여김. 즉 개도국의 경제적 성장과 빈곤감소를 지원하기 위해 정책과 정부 부처간의 시스템 통합 을 의미함.

$\square$ 정부 전체적인 차원에서의 개선 - 호주정부와 AusAID

- 국익이 개발아젠다 논의를 독점하고 빈곤감소 보다는 안보에 중점을 둘 가능성이 있음. 비록 안보와 안정이 빈곤감소의 전제조건이라 할지 라도 AusAID는 전체적인 정부접근안에서 개발 원조정책의 초점을 빈곤에 맞추도록 노력해야 함. 대테러와 같은 중요한 이슈도 개발아젠더에
우선하지 않도록 해야 함.

- AusAID 외 정부부처와 기관이 집행하는 ODA 의 비율이 점차 증가하고 있음. 이는 2004-05 년동안 $20 \%$ 를 차지하였으며 원조프로그램의 전체 증가의 $74 \%$ 를 차지함.

2. 주요이슈

1) 무역정책

$\square$ 호주는 무역자유화를 강조하고 주변 개도국들이 국제무역을 통한 이익을 극대화하여 빈곤을 경감 할 수 있도록 협력하고 있음. 2003년 7월부터 최빈 개도국(LDCs) 상품에 대한 관세와 쿼터를 모두 철 폐하였음.

$\square$ 2001년 이후 무역관련 기술협력과 역량강화 부문 을 강조함. 다자간 기구 및 펀드에 출자함과 동시 에 양자간 협력을 통해 위생과 농산물위생에 관련 한 기술원조를 AusAID와 정부 각 부처들을 통해 제공하고 있음. 무역자문그룹은 동 기술원조를 모 니터링하고 평가하며 무역과 개발이슈에 대한 기 술자문을 제공함.

$\square$ AusAID와 외무무역부의 무역협상부서와 정례고 위급회담을 가지며 도하라운드 호주 협상팀에 AusAID도 참여하여 호주 무역정책에 개발이슈를 반영하도록 하고 있음.

2) 언타이드 원조

$\square 2002$ 년 최빈개도국에 대한 개발원조의 $52 \%$ 가 조 건뷔(타이드)였음. 이는 19개 DAC 회원국 중 네번 째로 높은 타이드원조 비율임. 
- 이후 점차적으로 타이드비율을 줄여왔으며 그 노력의 일환으로 2004년 최빈개도국에 대한 기 술협력 언타잉 독립 원칙(Free- Standing Technical Assistance to LDCs)을 적용하였음.

- 따라서 AusAID 의 기술지원 계약은 국적 자격 요건이 원칙적으로는 적용되지 않음. 이로서 AusAID와 관리 계 약 자 들 (Managing Contractors)은 수원국이나 국제 기술전문가를 개발원조분야에 활용할 수 있게 됨.

$\square$ 그러나 동 원칙은 최빈개도국 이외의 수원국에 대 해서는 적용되지 않음. 또한 최빈개도국에 대해서 도 치안, 국제범죄 등과 같은 호주의 국익에 직접 적인 영향을 미치는 민감한 사안에 대해서는 호주 와 뉴질랜드의 공급자로 제한될 수 있음.

\section{3) 기후변화}

$\square$ 태평양지역의 기후변화에 대한 취약성을 감소하 기 위해 노력함.

- 태평양지역 섬들이 기후의 변화를 모니터링할 수 있도록، 기후변화 및 해수면 상승 모니터링” 프로그램(1990)을 지원하고 있음.

- 현재로서는 모니터링의 역할에 그치고 있으나 향후 대응책 마련을 위해 노력할 것임.

4) 대테러정책

\section{$\square$ 대테러지원과 역량강화}

- 2003 04년에 인도네시아대테러정책에 천만 호 주달러를 지원하였고 필리핀의 대테러정책에 5 백만 호주달러, APEC 국가들의 대테러 역량강화
를 위해 15백만 호주달러를 펀드에 기부하였음.

$\square$ 호주 NGO들은 빈곤감소에 직접적으로 기여하지 않는 대테러정책지원의 규모가 증가하는 것에 대 해 우려를 표명함.

- 이는 비록 대테러정책이 지역의 안녕과 안정성 에 기여한다 할지라도 개발재원이 제한되어 있 다는 측면을 고려할 때 보다 많은 자원이 빈곤 감소에 쓰여야 한다고 주장함.

- 또한 굿거버넌스에 대한 호주의 기여도는 빈곤 근절과 인권보호에 어느 정도 영향을 미쳤는지 를 통해 평가되어야 한다고 주장함.

5) 난민 정책 및 실행

$\square$ 1951년 UN 협정과 1967년 조약에 부합하는 난민 의 지위나 망명자를 인정하고 있음. 인도주의 프 로그램을 포함하는 이민정책은 난민과 인도적인 도움이 필요한 이들에게 13,000 개(난민촌 6,000 개 포함)의 장소를 제공하여 정착할 수 있도록 하 고 있음.

※ 호주의 인도주의 프로그램은 세계 3대 정착프 로그램 중 하나임.

$\square$ 그러나 2001년 이민자법을 개정하여 비자가 없 는 망명자들을 나우루와 파푸아뉴기니로 보냄. 이들은 호주정부 재원으로 운영되는 임시 센터에 지내게 됨.

$\square$ 호주의 이민법과 억류(detention)정책은 인권단체 와 난민권리단체에 의해 강한 비난을 받고 있음. 이에 대해 호주정부는 이들은 불법적인 무국적자 들이기 때문에 억류된 것이고 이들에 대한 처우는 
국제인권의무에 준해 시행하고 있다고 함.

$\square$ 최근 1년간 동 임시센터의 여성과 아동의 수는 상 당히 줄어들었음.

3. 능력(capacity), 조화, 감독

1) 정책 조화와 메커니즘

$\square$ 위원회, 태스크포스, 서비스전달 전담기관, 일반 적인 정부체계 밖의 기관 등을 통해 정부전체적인 (whole of government work) 개발원조접근방식 을 취함.

- 예를 들면 솔로몬군도에 설치된 원조조정기관에 외무무역부, 국방부, 호주연방경찰청, AusAID 에서 각각 Senior officer를 파견하여 정부 전체 적인 접근방식을 취하려고 노력함.

$\square$ 외무무역부는 호주의 대외관계에 전체적인 책임 이 있으며 그외 정부부처는 특정이슈의 국제협상 에 관여함.

2) 업무수행와 협상기술: 전략적 파트너십 $\square$ 주요 정부부처간의 전략적 파트너십 협정 채택

- 정부 각 부처는 지역프로그램의 수행을 위해 부 처내 기관을 신설함.

$\square$ AusAID는 호주연방경찰청에 직원을 파견하여 법 체계확립을 통한 역량강화 프로그램의 정부전체 적인 접근이 가능하도록 함.

3) 외부전문가 활용과 내부 분석역랑의 강화

$\square$ AusAID는 연구기관 및 대학과의 장기 파트너십과 외부자문위원을 통해 중요한 정책지식을 확보함. $\square$ 또한 직원의 역량을 강화하여 외부전문가에 대한 의 존도를 낮추기 위해 노력함. 내부 분석역량 강화는 AusAID의 정치적 영향력을 강화할 것으로 기대됨.

4) 모니터링 메커니즘

$\square$ 2004년 AusAID내 정책일관성과 AusAID의 다른 정부부처와의 협력 효율성을 강화하기 위해

"Whole of- Governmnet Operational Support Unit"을 신설함.

$\square$ 개발원조 결과의 모니터링을 중요하게 여김.

- 현재 AusAID의 모니터링 메커니즘은 다른 정부 부처에 의해 집행되는 ODA에 적용되지 않으나 향후 동 건에 대한 논의가 확대되어야 할 것임.

\section{V. 개발원조 조직 및 관리}

\section{AusAID 연혁}

$\square$ 1946년 대 파푸아뉴기니 원조프로그램 실시 이래 다양한 정부부처에서 시행해 오던 원조기능을 통합 하여 1974년에 ADAA(Australian Development Assistance Agency) 설립

$\square$ 1976년에 ADAA를 ADAB(Australian Development Assistance Bureau)로 개편하고 외무무역부 산하에 둠. 1987년에 $\mathrm{ADAB}$ 를 AIDAB(Australian International Development Assistance Bureau)로, 1995년에는 AIDAB을 AusAID(Australian Agency for International Development)로 각각 개편 


\section{2. 조직구조}

\section{$\square$ 청장(Director General)}

- AusAID의 운영 및 활동을 총괄 지휘하고 외무 장관(Minister)과 Parliamentary Secretary to the Minister for Foreign Affairs에게 원조 정책과 운영에 관하여 보고. 집행위원회 (AusAID Executive)로부터 보좌를 받음.

\section{$\square$ 집행위원회(AusAID Executive)}

- 청장 및 3명의 부청장(Deputy Director General)으로 구성

- 전략적 방향의 설정과 전반적인 운영관련 이슈 논의

- 집행위원회는 12명으로 구성된 Policy Reference Group으로부터 보좌를 받음.

$\square$ 원조자문위원회(Aid Advisory Council)

- 외무장관에게 원조프로그램의 기획 및 실시에 관한 독립적이고도 전문적인 자문 제공

- 위원은 학계, 민간부문, NGO, 지역사회의 저명 인사 중에서 선발

- 외무장관이 동 위원회의 의장직을 수행

$\square$ 개발협력위원회(Committee for Development Cooperation)

- AusAID 및 NGO 각각 6명으로 구성된 총 12명 의 자문위원회

- 주요기능으로서 AusAID 자금지원을 희망하는 $\mathrm{NGO}$ 에 대한 평가, $\mathrm{NGO}$ 관련 정책, AusAID의 $\mathrm{NGO}$ 협력프로그램에 관한 운영 역할 수행 $\square$ 이밖에 심사위원회, 인사기획자문그룹, 정보관리 자문그룹 등이 있음.
3. 정책과 전략의 관리 및 운영

$\square$ AusAID 전략계획(2001): 변화하는 환경 속의 원 조효과성 제고

- AusAID 프로그램의 질 항상

- 기관의 정책과 분석역량 강화

- 인사 및 기관시스템의 발전

$\square$ 동 전략계획은 지난 2년간 다음과 같은 방향으로 집행됨.

-“ 수원국가내(in- country) 활동운영 이양” 지원: 분권화

- 프로그램의 전략적 방향성 강화

- 유연성있고 개혁적인 프로그래밍 및 계약 메커 니즘 활용

- 업무체계 능률화

- 다른 정부부처, 다자기구, NGO들과의 협력강화 $\square$ 전략계획은 원조프로그램을 새롭게 만들기 위한 포괄적인 방법을 제시하고 관리의 긍정적인 변화 를 가져옴.

\section{4. 조직운영과 인사관리의 일치}

$\square$ 해외사무소로의 프로그램운영에 대한 권한이양 - 우수한 외국 혹은 현지 직원을 활용할 수 있음. 이러한 경향은 국가별 분석 및 평가를 통해 확 산되고 있음. 이는 AusAID의 해외사무소 역량 의 강화를 요구함.

$\square$ 평가중심

- 프로그램의 전략적 결과물과 성과중심운영접근 에 초점을 맞추고 평가' 노력을 가속화하고 있음. - 평가기능의 독립성을 확보하기 위해 AusAID는 
평가부서(the Office of Review and

Evaluation)와 청장사이의 상하관계가 아닌 명 확한 책임선을 규정함.

\section{$\square$ 인사관리 전략}

- 연구기관과의 장기적 파트너십과 자문위원의

임명을 통해 정책과 기술지식에 대한 접근성을

높이고자 애씀.

- 내부인력에 대한 지속적인 투자

- 그러나 잦은 인사이동은 수원국 정부와 지속적 인 관계를 형성하는데 걸림돌이 되고 있으며 원 조전달의 질에 부정적인 영향을 미침.

- 현재 AusAID는 이점을 인식하고 해외파견기간
의 연장을 고려하고 있음.

$\square$ 해외사무소로의 분권화와 함께 파견기간 연장은 현장경험을 쌓고자 하는 직원들에게 긍정적인 반 응을 얻을 수 있음.

\section{DAC의 주요 권고사항}

$\square$ 원조정책 및 대국민 인식

- 빈곤감소, 거버넌스, 안보, 정부전체적인 접근 의 관계가 향후 정책 기조에 반영되어야 하며 빈곤감소가 집행, 모니터링, 평가의 초점이 되

$<A$ usA ID 조직도>

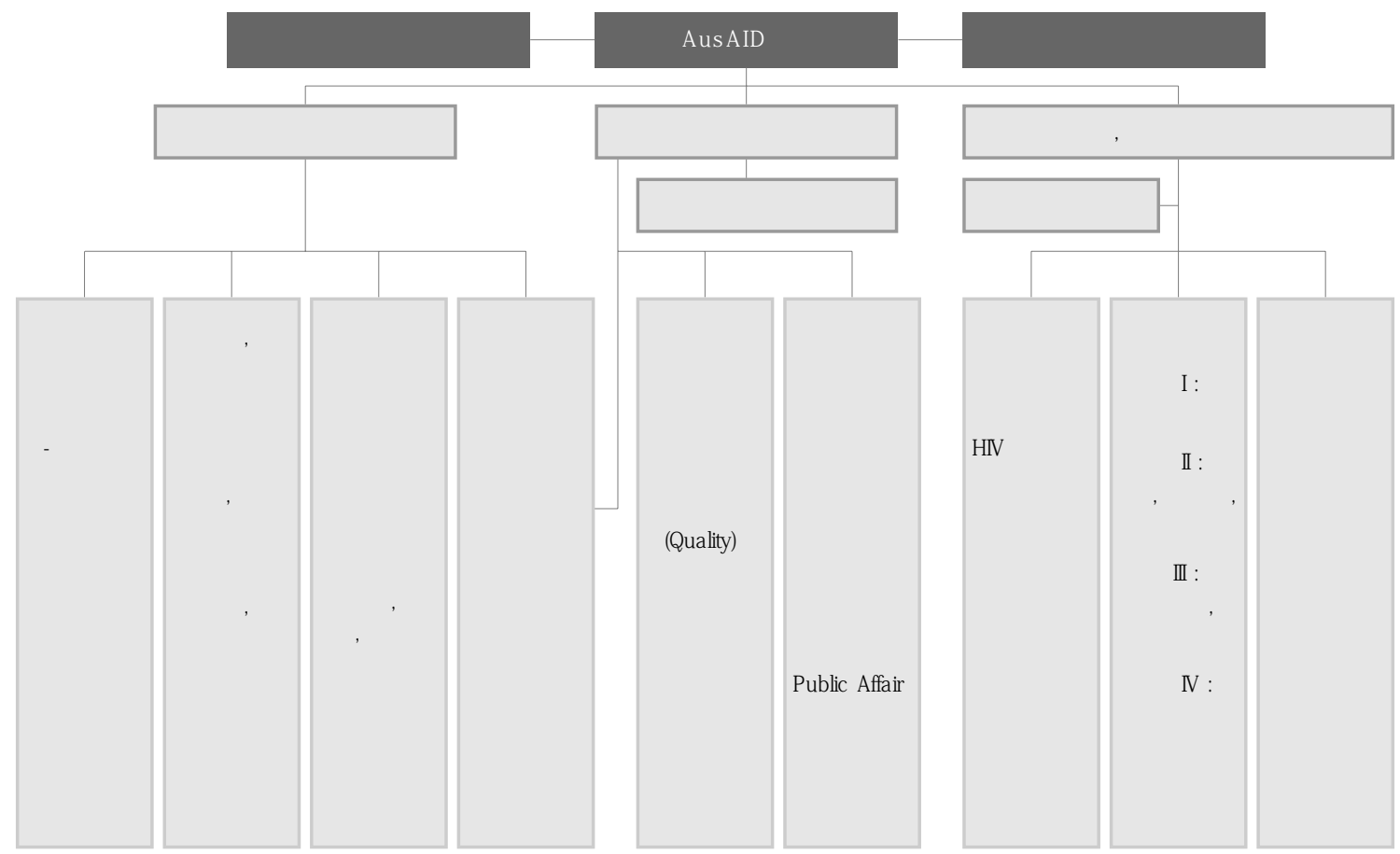


어야 함.

- 거버넌스 프로그램이 빈곤감소, 역량강화, 주인 의식에 미치는 영향을 지속적으로 평가하여 향후 빈곤감소를 위한 통합적인 접근을 시도해야 함.

- 지구적 교육프로그램을 통해 국제개발이슈에 대한 폭넓고 심도있는 논의가 이루어질 수 있도 록 해야 함.

- 취약국가의 지원은 MDGs의 달성과 국제안보 차원에서 중요함.

$\square$ 원조규모와배분

- ODA/GNI 0.7\%달성을 위한 중장기 목표를 발 표할 것

- 양자간 원조와다자간 원조 사이의 균형이 요구됨. $\square$ 정책일관성

- 정책일관성을 위한 노력을 지속해야 함. 정부부 처간 위원회에 전문지식을 제공하여 정부전체 적인 접근에 영향을 미치기 위해서는 자체 분석 역량을 강화하여야 함.

\section{$\square$ 원조관리 및 실행}

- 각 케이스별로 권한이양을 가속화시키고 본부 와 해외사무소간의 역할을 명확히 해야 함.

- 전문가의 기술이 효율적, 효과적으로 활용될 수 있도록 노력해야 하며 내부역량과 프로그램이 필요로 하는 것이 일치하도록 해야 함.

- 평가기능의 독립성을 확보하기 위해서 청장실 과 평가실사이의 명확한 책임구분이 있어야 함. 